\title{
Measuring the relative efficiency of project management using data envelopment analysis
}

\author{
Sara Orouji ${ }^{\mathrm{a}^{*}}$
}

${ }^{a}$ Growing Science, Toronto, Canada CHRON I C L E

\section{A B S T R A C T}

Article history:

Received: October 1, 2016

Received in revised format: November 16, 2016

Accepted: January 20, 2017

Available online:

January 20, 2017

Keywords:

DEA

Project management

Efficiency

\begin{abstract}
Measuring the relative efficiency of similar units has been an open research for years. Data envelopment analysis (DEA) has been widely used among researchers for efficiency measurement. DEA uses different inputs/outputs to measure the relative efficiency of one unit compared with other similar units. This paper presents a comprehensive review on recent applications of DEA techniques on measuring the relative efficiency of project management units. The study covers the implementation of DEA method for measuring the relative efficiency of enterprise resources planning, research and development and construction projects.
\end{abstract}

\section{Introduction}

For years, there have been significant efforts to implement data envelopment analysis (DEA) for measuring the relative efficiency of similar units (Charnes et al., 1978; Banker et al., 1984). DEA has been commonly applied when input/output are not measurable by applying financial figures. For example, in educational systems, one may be interested in promoting schools with students who reach academic excellence. In electricity industry, there are many units in the world, which are reporting lost in their statements due to various reasons and any additional budgets must be based on non-financial numbers such as the number customers covered, the volume of electricity transmitted, etc. Fig. 1 shows a sample of different factors influencing on efficiency measurement. In a DEA method, there are some inputs/outputs associated with all decision-making units. Let $x_{i j}$ be the inputs for one of a particular unit with $i=1, \ldots, m$ and $y_{r j}$ be the outputs of other units with $r=1, \ldots, s$ and $j=1, \ldots, n$ and let $u_{i}$ and $v_{j}$ be the dual variables associated with $x_{i}$ and $y_{j}$, respectively. The constant return to scale DEA model is formulated as follows,

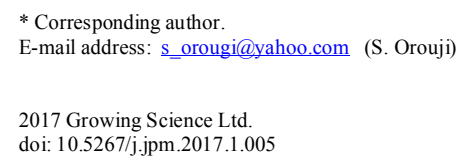




$$
\begin{array}{cc}
\max & z=\frac{\sum_{r=1}^{s} u_{r} y_{r .}}{\sum_{i=1}^{m} v_{i} x_{i .}} \\
\text { subject to } \quad & \frac{\sum_{r=1}^{s} u_{r} y_{r j}}{\sum_{i=1}^{m} v_{i} x_{i j}} \leq 1 . \\
& x_{i j}, y_{i j \geq 0}
\end{array}
$$

Model (1) is the original DEA, which can be executed $j$ times to measure the relative efficiencies of different units. Since model (1) is nonlinear in structure, Charles et al. (1978) proposed a method to convert model (1) into a simple linear programming problem as follows,

$$
\begin{array}{ll}
\max & z=\sum_{r=1}^{s} u_{r} y_{r .} \\
\text { subject to } & \frac{\sum_{r=1}^{s} u_{r} y_{r j}}{\sum_{i=1}^{m} v_{i} x_{i j}} \leq 1 . \\
& \sum_{i=1}^{m} v_{i} x_{i .}=1 \\
& u_{r}, v_{i} \geq 0, \quad j=1, \ldots, n
\end{array}
$$

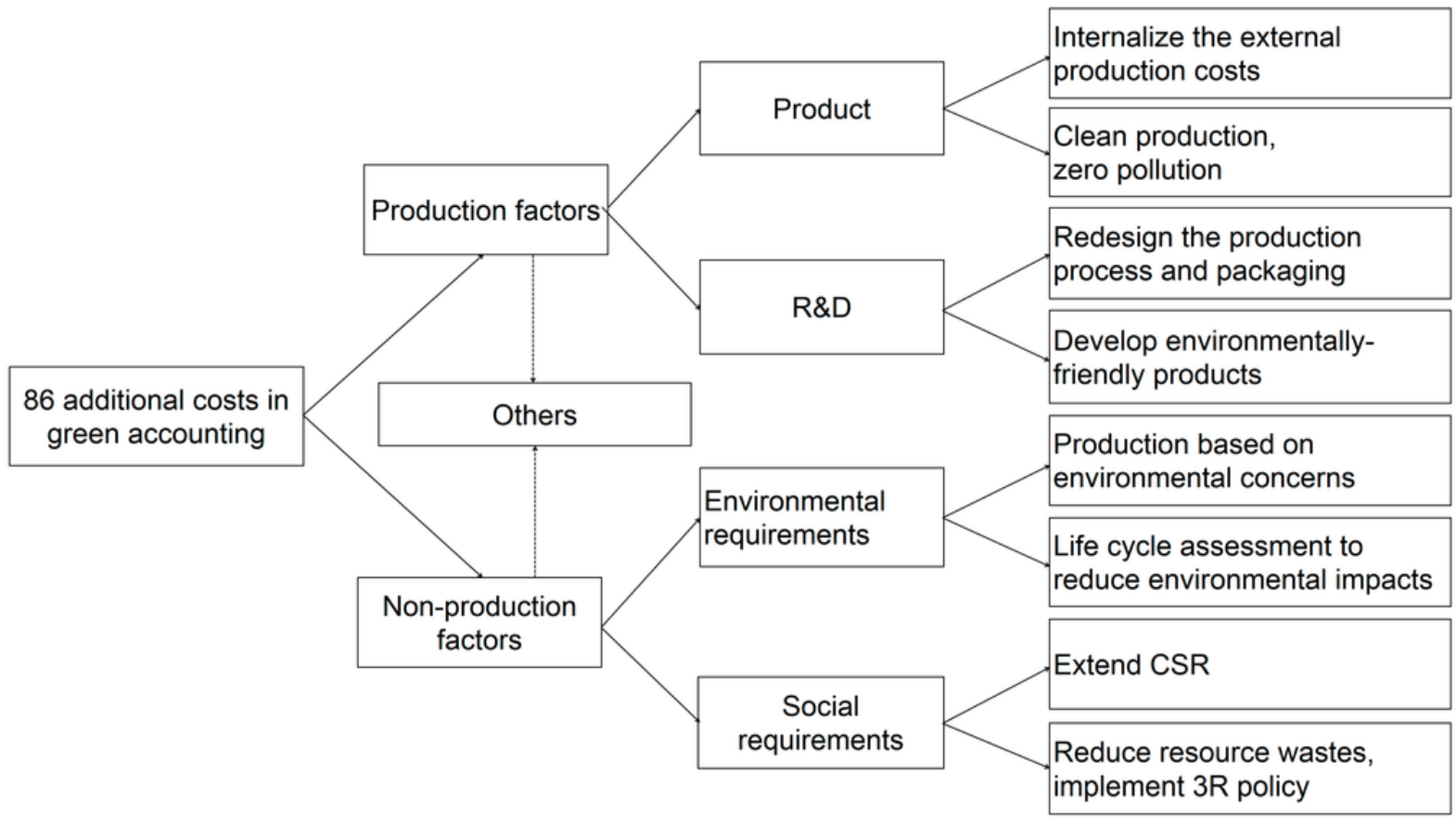

Fig. 1. A scheme representing different input/output influencing efficiency of project management

There are several applications of Malmquist productivity index (Aparicio et al., 2013; Kerstens \& Van de Woestyne, 2014). Woo et al. (2015) studied the environmental efficiency of renewable energy from the static as well as the dynamic perspective in 31 OECD countries to get some insight about the effect 
of renewable energy across different countries. In their study, DEA method was implemented to measure environmental efficiency through multiple inputs/ outputs. Besides, to measure the dynamic environmental efficiency of renewable energy, the Malmquist productivity index was used to forecast the average efficiency change.

Wijesiri and Meoli (2015) used a DEA based Malmquist technique to investigate the changes in productivity of some Kenyan microfinance institutions (MFIs) from 2009 to 2012. A bootstrap procedure was also implemented to detect whether the changes in Malmquist index and its components were statistically significant. They reported that MFIs had experienced about $7 \%$ annual productivity progress on average. Another bootstrapped regression analysis was also applied to study the impact of various environmental variables on productivity change measures and the results stated that matured MFIs maintained a lower productivity compared with their other counterparts. Lin and Du (2015) developed a methodology for modeling the dynamic of carbon emission performance. They developed a parametric Malmquist index method that takes into account statistical noises and implemented the fixed-effect panel stochastic frontier model to deal with regional heterogeneity. The method was used to study the dynamics of carbon emission performance in 30 Chinese provinces.

Fuentes and Lillo-Bañuls (2015) studied the productivity growth of the SUMA tax offices located in Spain evolved over the period 2004-2006 using Malmquist Index based on DEA models. Zhang et al. (2015) used a Malmquist $\mathrm{CO}_{2}$ emission performance index (NMCPI) for computing dynamic changes in total-factor $\mathrm{CO}_{2}$ emission performance over time. They reported that the total-factor carbon emission performance of the transportation industry as a whole decreased by $32.8 \%$ because of technological decline. Gharneh et al. (2014) applied bootstrapping Malmquist index to derive the productivity levels of Iranian steam power plants from 2007 to 2012. They reported that the average level of productivity significantly decreased and also reported that technological changes had more effects on productivity than efficiency changes. Ahn and Min (2014) studied the multi-period operating efficiency of international airports based on DEA and the Malmquist productivity index. Ulucan and Atic1 (2010) made an assessment on the efficiency of decision making units (DMUs) in a World Bank supported Social Risk Mitigation Project (SRMP) in Turkey using context-dependent and measure-specific DEA techniques. They reported that the efficiency evaluations with context-dependent and measure-specific DEA play various roles in an organization such as setting attainable targets to DMUs, setting long and short term targets to DMUs separately, grouping of DMUs, and contributing internal competition between DMUs. They showed the applicability of context-dependent and measure-specific DEA methodologies in a World Bank supported large scale project to increase the effectiveness of the project. They also outlined some important managerial conclusions of context-dependent DEA clustering method. Moreover, they proposed an alternative method for attractiveness scores computations in case of exogenous group formations.

\section{Project management}

DEA technique has also been used in measuring the efficiency of project management methods. Trindade et al. (2015) used DEA method for measuring project management efficiency of a Portuguese electricity distribution utility. Kwon et al. (2017) proposed an innovative three-stage model using DEA and backpropagation neural network (BPNN) for supporting 'better practice' benchmarking as contrasted with the traditional 'best practice' benchmarking. They reported that DEA models could provide the capability of setting optimal objectives, but the drawback of the standard DEA method was its inability to give actionable targets necessary for incremental improvement. Overcoming the shortfalls of DEA and its superiority-driven practices, the BPNN method accommodates stepwise improvement through adaptive learning and prediction capability. Therefore, the proposed three-stage model was capable of creating feasible improvement options for decision makers as an intelligent decision support tool. At its core, the innovative approach gives a promising method for shaping a 'better practice' paradigm. 


\subsection{ERP projects}

Enterprise Resource Planning (ERP) packages developed by ERP vendors are intended not only to standardize the existing business processes of the using organization, but also to offer some of the best practices of the industry. There are different studies on the assessment of the efficiency of standard ERP projects. Evaluating the efficiency of customized ERP packages is necessary for benchmarking best customization practices. Parthasarathy and Sharma (2016) investigated the efficiency of customized ERP software packages based on DEA. They also studied the relationship between the degree of customization of ERP packages and the efficiency. The results implied that customization adversely influenced on the efficiency of ERP packages. Sudhaman and Thangavel (2015) analyzed the efficiency of ERP projects based on their quality measures (defect counts) using the DEA model and identified the most efficient ERP projects. Such projects serve as potential role techniques and the quality processes of these projects may be used by the future ERP projects leading to successful implementation.

\section{2. $R \& D$ projects}

Research and Development (R\&D) project teams are concerned with efficiency under limited resources must cohesively coordinate cooperation, interactions, and the exchange of ideas to sustain innovation. Hung (2017) studied the management of social networks, technology ties, and gatekeeper functionality from a networking perspective and investigated their contribution to R\&D performance, which was assessed using DEA method. The study confirmed the relationships by applying data from the Taiwan National Telecommunication Program, which coordinates more than 100 R\&D teams in pursuing nextgeneration broadband technologies. The density of social networking and the outward- and novel-oriented gatekeeper functionality of a project team, in this study, was determined to substantially promote its R\&D performance, whereas the density of technology ties presented no meaningful result. They also presented strategic implications for the management of projects, team interorganizational linkages, and governmental subsidy policies, and discussed the networking activities of R\&D teams at the project level.

El-Mashaleh et al. (2010) utilized DEA to benchmark safety performance of construction contractors. The proposed method was deployed based on some data gathered from 45 construction contractors. Vitner et al. (2006) studied the possibility of applying the DEA method for assessing the performances of different projects in a multi-project environment. Projects are assessed by the earned value management system and the multidimensional control system techniques. Karasakal and Aker (2016) applied multiple criteria sorting methods based on DEA to evaluate R\&D projects. The weight intervals of the criteria were calculated from Interval Analytic Hierarchy Process and used as the assurance region constraints of models. According to DEA method, two threshold estimation models, and five assignment models were developed for sorting. Moreover, these models also provided ranking of the projects. The proposed method and the well-known sorting method UTADIS were implemented for a real case study to analyze the $R \& D$ projects proposed to a give program executed by a government funding agency in 2009. Lu et al. (2016) implemented a network DEA model called network slacks-based measure (NSBM) to investigate the R\&D efficiency and socio-economic efficiency of Taiwan's dualuse (military and general public) technology development programs. They also used the additive superefficiency model to determine programs at various stages and conducted an analysis on the strengths and weaknesses of internal resource utilization. They reported that the R\&D efficiency was substantially higher than the socio-economic efficiency.

\subsection{Construction projects}

Nazarko and Chodakowska (2015) applied DEA and Tobit regression for analyzing productivity of the construction industry in Europe and measured labor productivity using with DEA method. The results disclosed big differences in the productivity of the construction industry across Europe. On the basis 
of regression analysis it was proven that the interpretation of the efficiency scores without considering the general economic conditions of a country could lead to false conclusions. Shuqiang and Qiankun (2012) proposed the engineerization management method, discussed the connotation and main contents of engineerization management, and implemented the DEA method in performance evaluation of engineerization management.

Sustainability was used by several firms through their mission statement and strategy but social and environmental dimensions of sustainability are difficult to use in programs and projects. Sánchez (2015) developed a framework to learn whether or not an organization is working on the right projects to gain its business strategy and stakeholders demands. The study addressed both the portfolio selection problem and the project tracking phase. The portfolio selection helps selecting the better mix of projects based on analysis of eco-effects and contribution to organizational goals. Both selection and monitoring were modeled as an optimization problem and provided a tool for integrating sustainability and project management in operational terms.

\section{Conclusion}

In this paper, we have performed a survey on recent advances on the DEA applications on performance measurement of projects. The review shed insight on the importance of ERP projects and presented different studies on DEA based method for performance measurement. Research and development projects are other important items which are considered in most organizations and our survey has indicated that using DEA method could significantly contribute on measuring performance measurement in this industry. Finally, construction projects are also under productivity measurement using DEA analysis.

\section{Acknowledgement}

The authors would like to thank the anonymous referees for constructive comments on earlier version of this paper.

\section{References}

Ahn, Y. H., \& Min, H. (2014). Evaluating the multi-period operating efficiency of international airports using data envelopment analysis and the Malmquist productivity index. Journal of Air Transport Management, 39, 12-22.

Aparicio, J., Pastor, J. T., \& Zofio, J. L. (2013). On the inconsistency of the Malmquist-Luenberger index. European Journal of Operational Research,229(3), 738-742.

Banker, R. D., Charnes, A., \& Cooper, W. W. (1984). Some models for estimating technical and scale inefficiencies in data envelopment analysis. Management science, 30(9), 1078-1092.

Charnes, A., Cooper, W. W., \& Rhodes, E. (1978). Measuring the efficiency of decision making units. European Journal of Operational Research, 2(6), 429-444.

Fuentes, R., \& Lillo-Bañuls, A. (2015). Smoothed bootstrap Malmquist index based on DEA model to compute productivity of tax offices. Expert Systems with Applications, 42(5), 2442-2450.

Gharneh, N. S., Nabavieh, A., Gholamiangonabadi, D., \& Alimoradi, M. (2014). Productivity change and its determinants: Application of the Malmquist index with bootstrapping in Iranian steam power plants. Utilities Policy, 31, 114-120.

Hung, C. L. (2017). Social networks, technology ties, and gatekeeper functionality: Implications for the performance management of R\&D projects. Research Policy, 46(1), 305-315.

Karasakal, E., \& Aker, P. (2016). A multicriteria sorting approach based on data envelopment analysis for R\&D project selection problem. Omega, To appear.

Kerstens, K., \& Van de Woestyne, I. (2014). Comparing Malmquist and Hicks-Moorsteen productivity indices: Exploring the impact of unbalanced vs. balanced panel data. European Journal of Operational Research, 233(3), 749-758. 
Kwon, H. B., Marvel, J. H., \& Roh, J. J. (2017). Three-stage performance modeling using DEA-BPNN for better practice benchmarking. Expert Systems with Applications, 71, 429-441.

Lin, B., \& Du, K. (2015). Modeling the dynamics of carbon emission performance in China: A parametric Malmquist index approach. Energy Economics, 49, 550-557.

Lu, W. M., Kweh, Q. L., Nourani, M., \& Huang, F. W. (2016). Evaluating the efficiency of dual-use technology development programs from the R\&D and socio-economic perspectives. Omega, 62, 8292.

Nazarko, J., \& Chodakowska, E. (2015). Measuring productivity of construction industry in Europe with Data Envelopment Analysis. Procedia Engineering, 122, 204-212.

El-Mashaleh, M. S., Rababeh, S. M., \& Hyari, K. H. (2010). Utilizing data envelopment analysis to benchmark safety performance of construction contractors. International Journal of Project Management, 28(1), 61-67.

Ulucan, A., \& Atıc1, K. B. (2010). Efficiency evaluations with context-dependent and measure-specific data envelopment approaches: An application in a World Bank supported project. Omega, 38(1), 68-83.

Parthasarathy, S., \& Sharma, S. (2016). Efficiency analysis of ERP packages - A customization perspective. Computers in Industry, 82, 19-27.

Sánchez, M. A. (2015). Integrating sustainability issues into project management. Journal of Cleaner Production, 96, 319-330.

Shuqiang, W., \& Qiankun, W. (2012). Effect evaluation of construction engineerization management for military projects. Systems Engineering Procedia, 3, 351-356.

Sudhaman, P., \& Thangavel, C. (2015). Efficiency analysis of ERP projects-software quality perspective. International Journal of Project Management, 33(4), 961-970.

Trindade, D., Barroso, A. P., \& Machado, V. H. (2015). Project management efficiency of a Portuguese electricity distribution utility using data envelopment analysis. Procedia Computer Science, 64, 674-682.

Vitner, G., Rozenes, S., \& Spraggett, S. (2006). Using data envelope analysis to compare project efficiency in a multi-project environment. International Journal of Project Management, 24(4), 323329.

Wijesiri, M., \& Meoli, M. (2015). Productivity change of microfinance institutions in Kenya: A bootstrap Malmquist approach. Journal of Retailing and Consumer Services, 25, 115-121.

Woo, C., Chung, Y., Chun, D., Seo, H., \& Hong, S. (2015). The static and dynamic environmental efficiency of renewable energy: A Malmquist index analysis of OECD countries. Renewable and Sustainable Energy Reviews, 47, 367-376.

Zhang, N., Zhou, P., \& Kung, C. C. (2015). Total-factor carbon emission performance of the Chinese transportation industry: A bootstrapped non-radial Malmquist index analysis. Renewable and Sustainable Energy Reviews, 41, 584-593.

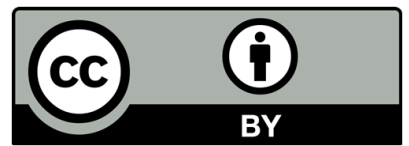

(C) 2017 by the authors; licensee Growing Science, Canada. This is an open access article distributed under the terms and conditions of the Creative Commons Attribution (CC-BY) license (http://creativecommons.org/licenses/by/4.0/). 